Foureur MJ, Leap N, Davis D, Forbes I, Homer CSE. (2011) Testing the Birth Unit Design Spatial Evaluation Tool (BUDSET). Health Environments Research and Design Journal 4(2): 22-41.

\title{
TESTING THE BIRTH UNIT DESIGN SPATIAL EVALUATION TOOL (BUDSET) IN AUSTRALIA: A PILOT STUDY
}

\begin{abstract}
Objective: To pilot test the Birth Unit Design Spatial Evaluation Tool (BUDSET) in an Australian maternity care setting to determine whether such an instrument could measure the optimality of different birth settings.
\end{abstract}

Background: Optimally designed spaces to give birth are likely to influence the ability for a woman to experience physiologically normal labour and birth. This is important in the current industrialised environment where increased caesarean section rates are causing concerns. The measurement of an optimal birth space is currently not possible as there are limited tools available.

Methods: A quantitative study was undertaken to pilot test the discriminant ability of the BUDSET in eight maternity units in New South Wales, Australia. Five auditors trained in the use of the BUDSET assessed the birth units using the BUDSET. The BUDSET is based on 18 design principles and is divided into four domains (Fear Cascade; Facility; Aesthetics; and, Support) with 3-8 assessable items in each. Data were independently collected in eight birth units. Values for each of the domains were aggregated to provide an overall Optimality Score for each birth unit.

Results: A range of Optimality Scores was derived for each of the birth units (from 51 to 77 out of a possible 100 points). The BUDSET identified units with low scoring domains. Essentially these were older units and conventional labour ward settings. 
Conclusion: The BUDSET provides a way to assess the optimality of birth units and determine which domain areas may need to be improved. There is potential for improvements to existing birth spaces and considerable improvement can be made with simple low cost modifications. Further research is needed to validate the tool. 


\section{AUTHOR INFORMATION}

\section{Maralyn J. Foureur}

RM, BA, Grad Dip Clin. Epi, PhD

Professor of Midwifery

University of Technology Sydney \& Northern Sydney Central Coast Area Health Service PO Box 123, Ultimo, Sydney, NSW, 2007

Email: Maralyn.foureur@uts.edu.au

Tel: +61+2 95144835

Fax: $+61+295144834$

Nicky Leap

RM, MSc, DMid

Professor of Midwifery Practice Development and Research

University of Technology Sydney \& South East Sydney and Illawarra Area Health

Service

Email: Nicky.leap@uts.edu.au

Deborah L Davis

$\mathrm{RM}, \mathrm{BN}, \mathrm{MNS}, \mathrm{PhD}$

Associate Professor of Midwifery Practice Development and Research

University of Technology Sydney \& South East Sydney and Illawarra Area Health

Service

Email: Deborah.davis@uts.edu.au

Ian F.W. Forbes

Adjunct Professor of Architecture

University of Technology Sydney and Health Facilities Planning, Designinc Architects

Email: iforbes@sydney.designinc.com.au.

Caroline S.E. Homer

RM, MSci Med (Clin Epi), PhD

Professor of Midwifery

University of Technology Sydney

Email: Caroline.homer@uts.edu.au 


\section{INTRODUCTION}

The environment in which health care occurs has substantial effects on patient health and safety, care effectiveness, staff efficiency and morale (Ulrich \& Barach, 2006). Each year in Australia and many developed countries, expenditure on the building or refurbishment of health facilities is large, for example, an estimated \$A5.3 billion in 2006-07 (AIHW, 2008). Facility Design and Post Occupancy Evaluation Guidelines provide a generic set of principles and mandatory requirements to ensure the building of physical environments that support and enhance the delivery of high standards of patient care. The guidelines consider models of care, access, mobility, occupational health and safety, security, infection control and more. Recent advances in cross disciplinary studies linking architecture and neuroscience have however, revealed that much of the built environment for health care delivery may actually impair rather than improve health outcomes by increasing patient and staff stress (Stichler \& Kirk Hamilton, 2008; Ulrich et al., 2008). Stress initiates and exacerbates illness and impacts on the quality of communication between patients and staff and between staff, and poor communication increases the risk of medical errors and adverse patient outcomes. Therefore current facility guidelines require radical revision in the light of emerging evidence.

THIS IS THE PULL-OUT QUOTE. Birth facilities are of particular interest in considering a link between design and outcomes since pregnant women are generally healthy and pregnancy and childbirth are usually considered to be normal life events rather than an illness or disease. Several studies and writers have considered the impact of spaces built for women giving birth in hospital settings and how these environments may impact on maternal and infant outcomes (Davis \& Walker, 2009; Foureur, 2007; Lepori, 2008; Lock \& Gibb, 2003; Newburn \& Singh, 2005; Symon, 2008a; Walsh \& Downe, 2004; Hodnett et al., 2009; Hauck et al., 2008). This study builds on this growing body of knowledge by testing a set of design principles in an assessment tool to measure the optimality of different birth settings (Foureur, et al 2009). 
We have developed a conceptual model as a framework for examining optimality in the large study of which this pilot study is one part. The conceptual model is based on the premise that birth units that are optimally designed facilitate effective communication, decrease both women's and staff stress and thereby provide the best opportunity for women to experience a safe and satisfying labour and birth. The conceptual model describes the relationships among this set of variables as: Safe, Satisfying Birth (SSB) is a function ( $f$ ) of the Woman's Stress level and Communication with the woman (WS+CW) that may be influenced by Staff Stress and Communication among staff (SS+CS), and these factors are mediated (reduced or increased) by Birth Unit Design and Model of Care (BUD+MOC). Much research has focused on the effectiveness of different models of care without considering the potential confounder of Birth Unit Design (Hatem et al., 2008). This pilot study aims to examine the area of Birth Unit Design in more depth.

There is increasing evidence articulating how the design and aesthetics of the spaces we inhabit, impact on our physicality, behaviour, neurophysiology and wellbeing (de Botton, 2006; Dilani, 2001; Edelstein, 2004; Fleming, Baum, \& Singer, 1984; Ulrich \& Barach, 2006; Hodnett et al., 2009). Several recent studies have considered the impact of spaces built to house birthing women outside of their homes and how these environments may impact on maternal and infant outcomes (Forbes, Homer, Foureur, \& Leap, 2008; Foureur, 2008; Foureur \& Hunter, 2007; Hodnett, Downe, Edwards, \& Walsh, 2005; Lepori, Foureur, \& Hastie, 2008; Lock \& Gibb, 2003; Newburn \& Singh, 2005; Olsen \& Jewell, 2006; Symon et al, 2008a, 2008b, 2008c, 2008d; Walsh \& Downe, 2004). As birth in hospital is a relatively recent phenomenon with a focus on the acute and relatively rare occurrence of birth pathology (Donnison, 1977; Fahy, 2008; Shorter, 1983; Tew, 1990), hospital birth spaces now function as a technology of biomedicine. Institutional birth spaces are designed to accommodate this focus, however it is likely that these are counter to the facilitation of normal childbirth.

Optimal environments for women to labour and give birth are clearly required. The first step in this process is to be able to measure optimality. The measurement of an optimal 
birth space is currently not possible as there are limited tools available. There is also limited research into optimal birth unit design.

The aim of this pilot study was to determine whether a developed instrument, known as the Birth Unit Design Spatial Evaluation Tool (BUDSET) could measure the optimality of different birth settings and to explore how the instrument could be improved and refined. This is the first stage of a larger study that aims to assess whether optimal design influences outcomes for mothers and babies. The development of the BUDSET instrument and the underlying theoretical concepts were described in previous papers (Forbes et al., 2008; Foureur et al., 2010). This paper describes the results of the next phase of the study, that is, the pilot testing of the instrument in eight Australian birth units.

\section{METHODS}

This was a quantitative pilot study using the BUDSET.

\section{Setting}

The study was set in one area health service in New South Wales, Australia. This area health service includes metropolitan, regional and rural settings. Eight hospital birth units (designated as Hospitals A-F in this paper) situated in six hospitals in this area health service were selected. The birth units were representative of many birth units in Australia. In total, the birth units catered for around 10,500 births per year.

The birth units ranged in age and time since refurbishment (Table 1). Hospital A was a large tertiary hospital close to the city centre (Sydney). It was purpose-built for maternity care 12 years ago and has a birth centre and a labour ward. Birth centres in Australia are usually separate from the labour ward but often located in the same building. Birth centres are designed as a home-like alternative to a conventional labour ward with double beds and soft furnishings rather than obstetric beds. Birth centres cater for women who do not have risk factors and promote normal childbirth in their approach and philosophy. 
Labour wards, on the other hand, cater for women with a range of risk factors, from none to high risk.

Hospital B was built 18 years ago. It is a smaller unit with, again, both a birth centre and labour ward. Hospital B is in a more suburban area but is still classified as a metropolitan hospital. It caters for women who have risks but not at the highest level. Hospital C was purpose-built three years ago and is classified as being in an outer metropolitan area. It caters for women with minimal risk factors. If women have risk factors they are transferred to Hospital B as it is the closest referral unit.

Hospitals D, E and F are located outside of the city. Hospital D is the regional main hospital and caters for women with risk factors. The unit was built more than 20 years ago and has undergone minimal refurbishment. Hospitals $\mathrm{E}$ and $\mathrm{F}$ are small regional/rural hospitals with smaller numbers of births. Women with risk factors are transferred out of both of these hospitals, usually to Hospital D.

$<$ Insert Table 1 here $>$

\section{Data collection}

Data were independently collected by up to five researchers during a site visit to each of the birth units. At least four of the five researchers attended each of the eight birthing units. The researchers had been involved in the development of the BUDSET and were familiar with the domains and the scoring system. The definition of constructs such as 'appears safe', 'well lit', and 'easily navigable' were defined through discussions during the development of the tool. The BUDSET was provided to each researcher with a clip board. As the study did not involve access to patients, institutional ethical approval (institutional review board) was not required. The maternity unit directors at each site provided permission for the study to be undertaken.

Each researcher walked around the birth unit to score the relevant items using the BUDSET. No discussion or altering of scores based on consultation with one another 
took place. The site visits took, on average, one hour per unit. Informal conversations were held with staff present during the site visit and notes were taken of the discussions. We chose not to use equipment to measure the items (eg. measuring the noise levels with a meter) as we wanted to make the process of collecting data as simple as possible and something that clinicians and managers could ultimately undertake themselves.

\section{The BUDSET instrument}

The BUDSET is arranged into four domains. Each domain contains 3-5 measurable characteristics. The theoretical constructs behind each of these is described in a previous paper (Foureur et al., 2010).

The four domains measure:

1. Characteristics affecting the Fear Cascade

2. Facility characteristics

3. The Aesthetic aspects of the unit

4. The essential Support elements for women and families

A detailed description of the domains, each of the characteristics and the scoring is in Table 2.

$<$ Insert Table 2 here $>$

\section{Analysis}

The analysis was approached from a position reflecting compliance with the design principles of the BUDSET. Responses were entered into an Excel database for analysis. Weightings were applied to normalise the imbalance between items that had more subelements than those that did not. For example, the Fear Cascade domain has more measurable characteristics than the Support domain however to compare these with one another, the data were weighted using simple arithmetic processes. Values were generated for each of the domains which were then aggregated to provide an overall 
Optimality Score for each birth unit and a mean score for each domain. An analysis to examine internal validity was also undertaken by measuring the intra-class correlation coefficient (ICC) for the researchers across the eight sites. An ICC below 0.6 was indicated poor correlation between raters.

The findings present the Optimality Scores for each domain as well as details of the specific characteristics in each domain to highlight the differences and similarities between units. The results of the interval validity analysis are presented at the end of the next section.

\section{FINDINGS}

A total Optimality Score was derived for each of the birth units. This ranged from a low score of 51 (Hospital F) to the highest score of 77 (Hospital B's birth centre). The mean total score was 69 points. The age of the hospital was not strongly associated with the Optimality Score. The Labour Ward of a newer hospital (Hospital A) scored the lowest with the birth centres at Hospitals A and B and the Labour Ward in the newest hospital (Hospital C) scoring highest.

$<$ Insert Figure 1 here $>$

\section{Domain 1: Characteristics affecting the Fear Cascade}

Characteristics in Domain 1 include space (arrival area, outside area, reception area and the birthing room), sense of domesticity, privacy, noise control and universal precautions. The Optimality Scores for this domain ranged from 48 (Hospital F) to 82 (Hospital E) with a mean of 69 points. The scores indicated that these aspects were acceptable in the newer units but clearly presented major deficiencies in older units.

$<$ Insert Figure 2 here $>$ 
The arrival to the Birth Unit

It was determined that an ideal birth unit would have easy and direct access with little if any confusion as to direction or way finding. This reduces stress and provides assurance of safety. There was a clear access point for a person arriving at two of the units (Hospitals A and B). These were approached through the front lobby that served both the labour ward and the birth centre. In general however little, if any, consideration had been given to birthing units and their arrival points beyond what any unit or department within the hospital would expect. Where arrival was a central design concern, birthing units benefited; where not, they were generally unacceptable for anxious people arriving in a state of stress with concerns about the imminent birth of the baby.

Hospital C's unit was approached through the main entry with an impressive arrival space through a brightly lit foyer/court, with café and attractive community spaces giving a feeling of welcome. Unfortunately, once inside the building the birth unit was hard to locate. The birth unit in Hospital D had a separate vehicular entrance but was hard to find if one was unaware of its location. Once inside, access to the maternity unit was down a corridor, which was not well sign posted. The birth unit in Hospital E was approached from one side of the hospital, where a brightly lit corridor went directly to the unit. This was a very pleasant, stress free arrival space. Hospital F was the least acceptable as the only access to the hospital was a narrow road outside the maternity unit, which meant women were left alone while their companion parked the car. For many women the only familiar person in the hospital environment is their birth companion. If they are left alone with strangers, stress levels increase and the fear cascade can be initiated.

The short and longer term car parking in most hospitals was not close to the door or was often full or expensive, causing considerable travel to locate a park. The exceptions were Hospital A (where a new large underground parking lot is provided near to lifts into the main hospital complex) and Hospital B (a new multi-storey parking building was built in front of the hospital's entry). Otherwise, distance meant that the partner or support person could only quickly accompany the woman into the facility to ensure she was safe before moving the car. In all cases however, the arrival point was well lit to enable arrivals at 
night. Parking has generally become a major design problem for existing hospital sites. Provision is usually made for separated access to Emergency and the Main Entry. The recommended requirement for a separate entrance for birthing, especially with the frequency of late night arrivals now needs to be a fundamental consideration in hospital designs.

The arrival spaces and corridors varied. At Hospital B, the arrival was unattractive with corridors directly off the lift space with minimal signage indicating the location of either the birth centre or the labour ward. Hospital A also had long corridors, however these were more attractively decorated than Hospital B and while there are a lot of people around to provide a sense of security during the day, this would not be the case at night. This situation reflected the idea that birthing was another clinical space on the normal corridor system, with no consideration for psycho-social effects on arrival into an unwelcoming and potentially frightening environment.

Hospital D had its own entry, although the birth unit was down a corridor and around a corner. The corridor had windows to an inaccessible courtyard on one side but still felt welcoming. A similar experience occurred at Hospital C (being a newer hospital) but the distance was up a floor (by lift or stair) plus a long corridor. The view over a mezzanine level and out to tree-lined courtyards was a very positive aspect. Similarly the corridor from the drop-off area at Hospital E was a pleasant, sunny and welcoming experience. The worst case was the oldest building, Hospital F, whose birth unit had to be approached through a six-bedded ward. The afterthought nature of this unit reflected a concern to resolve the most immediate clinical design needs and little else.

Signage was generally poor in all hospitals. The corridors in the older hospitals were inevitably more drab and clinical. In all cases however, once inside the units, there was a pleasant reception desk with friendly faces welcoming arrivals.

All units had a reasonable hierarchy of spaces (public through to private) on arrival in the unit, especially the birth centres. The layout of the birth centre at Hospital A was through 
a public area into the corridor that linked the birth rooms and support spaces. Once into the large birth rooms, the usable space was evident and the atmosphere less clinical. Although smaller, the birth centre in Hospital B had a welcoming public arrival space, which led directly to two birth rooms, between which was a cupboard that provided supplies discretely from behind a curtain. This design, although in a 'smaller than ideal' renovated space, showed an understanding of good design principals and reflected its successful attempts to make the place "domestic" in feel.

The labour wards at Hospitals A, B, D and E were laid out as a standard hospital ward with double corridor systems and central staff bases. This often was softened by visual imagery in art work in the arrival place but inevitably the clinical nature of the environment dominated. Many corridors contained trolleys and equipment and the frequent visible staff movement along corridors into rooms left an institutional impression.

\section{Access to the outside}

There was outside space at Hospitals A and E. Hospital A had an outdoor deck area, which was virtually devoid of greenery, but provided an alternative place to go for women and supporters. The windows and the outdoor space were on the west of the building, which would be hot in the afternoon and untenable during an Australian summer. The outdoor space connected the various birthing rooms and, while a narrow strip, provided a place for mobilisation.

Hospital E's outdoor area was a garden courtyard that used screens to provide privacy. The screens also restricted the view of people passing along the entry corridor to the unit. The outdoor space was pleasant, however limited in its green elements, being covered in bark mulch, which was hard to walk on and tracked dirt into the room. This area did not provide colour or liveliness but was an opportunity for women to go outside. Clearly the cost of maintenance detracts from developing these important spaces. 
There were only two birth units with accessible gardens. Hospital A had windows and doorways to provide light and natural ventilation. Hospital D had large bright windows that looked out to the grounds, as did Hospital C; while both were pleasing and calming, they had no views of greenery. The environments were enhanced by views of the water and the city but had no access to a garden. The birth centre at Hospital B looked into an enclosed courtyard (a roof-top), which separated the two buildings and was unattractive, with no greenery. The labour ward at Hospital B similarly had windows that were able to provide natural light but the view was dominated by a neighbouring building, allowing only a glimpse of the grassy area at the front of the hospital. The louvers on the windows in were closed on most occasions since the window gave occupants the impression that people looking from the neighbouring building could see in.

At Hospital F there was no window at all and no direct access or view outside. These spaces gave the impression of inward task-oriented purposefulness and certainly were not stress reducing. It was clear that the value of outdoor spaces and green views has not been a consideration in these designs. With the extensive research in this area now available, not only natural light but access to the outdoors must be achieved in good birthing unit design in the future.

\section{The Reception Area}

There was a reception desk in all birth units where welcoming staff were evident, although the counters were high enough to be considered a barrier. The best compromise was the counter at Hospital E where stand-up writing spaces, as well as sit down conversation and interview spaces were provided. In the labour wards at Hospitals A, B and $\mathrm{D}$, triage and examination rooms were evident at the arrival area, therefore providing clear reminders that this was a clinical environment.

\section{The Birthing Rooms}

The birthing rooms were used as labour and birth rooms but generally not for postpartum care. Most birthing rooms were close to or larger than $25 \mathrm{~m}^{2}$. This was regarded as 
adequate space. The labour ward rooms in Hospital A were closer to $32 \mathrm{~m}^{2}$. Hospital F had one small and one larger room of which the latter was approximately $25 \mathrm{~m}^{2}$.

The bed is a critical element in setting the expression and impression of the birthing room. If the bed overtly reflects technical clinical procedures then the whole birth experience is likely to reflect this style of care.

Most labour ward rooms were entirely focussed on the bed. This probably came about in response to two main concerns; firstly because of an expressed need to fix the location of medical gases and power points usually in a location over or beside the bed. Secondly because of the assumption that the bed was where the woman would be located; therefore this was the place to use gas and other equipment. In some cases, portable gas was provided so that women can take gas to the bathroom and in other cases the tubes connecting the gas outlets to the 'gas delivery unit' were made longer to accommodate the woman's movement around the room. This whole configuration provides a predominant clinical expression even where the gas points were disguised behind panels or a cupboard. Recognition must be given to the design dichotomy of locating the gas outlets where they are likely to be used but at the same time understanding this may not be on the bed. Disguising, adapting and screening essential service points and location of the bed needs much more consideration in future.

The hospital style bed, although reinforcing the clinical feel of a room, was able to be elevated. In discussions, midwives indicated they usually raised it to form a leaning place for the woman or they lowered it so the woman could squat or lean against it to give birth on the floor. In many birthing centres the bed was fixed and domestic; in others the hospital style bed was moved away from the centre of the room to give women space to move about and change locations for the birth of the baby. The bed remains a major consideration in achieving good birthing room design.

Sense of domesticity 
In general, the two birth centres made deliberate attempts to provide homelike environments. The rooms had comfortable lounges and furniture deliberately intended to invoke home likeness. This sense was supported by the use of feminine artwork in the reception areas.

The labour wards were reflective of technical environments typical of hospital settings. This was reinforced by the corridor settings with staff stations and support room arrangements reflecting the layout of hospital wards. There were few if any birthingappropriate artworks in these other units.

The presence of fetal monitoring machines was evident sitting by the bedside at Hospital B's labour ward and in Hospitals F and D. This was an impediment to a homelike ambience especially on first arrival in the room. Fetal monitoring is not recommended in normal childbirth nonetheless, the machines are very evident, almost suggesting that they are necessary.

In the birth centres and labour wards in Hospitals A and B there were deliberate attempts to hide the equipment and supplies needed in the room. Metal trolleys were usually covered inside cupboards or covered storage arrangements. In Hospital B's labour ward they were hidden behind a concertina door which also covered the sharps box and rubbish bin. In Hospital A's labour ward, the extensive amount of supplies and storage was covered by drop blinds that could be raised or left down but were very often left raised for the convenience of the staff.

In all the units there were bedside tables for women's belongings but no full height cupboard space or lockable drawers. This is a major issue if the woman has to vacate the room in a hurry, for example, for an emergency caesarean section, sometimes resulting in a situation where the partner cannot accompany the woman as they have to safeguard the belongings or move them to another space, such as the postnatal ward. Priority instead was given for storage of equipment, linen or blankets. 
Privacy

In the labour wards, the birthing rooms opened directly onto a corridor. This was consistent with the current NSW Health Facility Guidelines and most typical hospital layouts. These rooms relied on cubicle curtains around the door for screening with a curtain track to create a small entry alcove. Hospital D had a very poor curtain track arrangement that did not curve inward to make an alcove and would be left open when the door was in use. Staff in all units agreed that a "knock before entering” policy was maintained but examination showed this provided no real protection for privacy.

The birth centres at Hospitals A and B were better designed with inner corridor systems that were not directly available to the public, providing a far better sense of privacy.

\section{Noise control}

The doors to each birth room were tested to determine whether an occupant could hear another woman nearby. Conversations could often be heard outside the door and it is likely that another woman could be overheard. This was a very negative aspect described by the NCT study undertaken in UK, where women felt very inhibited when thinking they could overhear or be overheard (Newburn \& Singh, 2005)

At Hospital E, noise could be heard from the hallway. At Hospital B's labour ward the noise from corridor activity was audible but we were assured that birthing noises in other rooms were not heard. On the other hand, the doors in the Hospital B birth centre were solid and no noise was heard. This was assisted by the corridor configuration, which provided a separate access way off the main traffic corridor.

Portable CD players or radios were available in all rooms for women to use. It was noted that at Hospital B the corridor speaker announces the end of visiting hours every day in multiple languages, which can be clearly heard in both birth units and was considered a very disrupting aspect. Apart from this, there were no corridor paging systems to disturb women. 


\section{Means to ensure universal precautions}

Domestic washbasins for women were provided in the bathrooms to all birth rooms.

There were other clinical basins equipped with antiseptic soap and wrist action taps. The exception was the birth centre at Hospital A where only a hand washbasin was available in the bathroom and the clinical basin was outside the door. This did allow for a less clinical feel as the basin needs an array of gloves and soap making it more intrusive but might not comply with the level of access necessary for current infection control procedures. Even at Hospital E where there was an unusual storage system that linked the birthing rooms and provided an alcove at the entry, the basin, waste bin and sharps disposal unit appeared intrusive in what might be a domestic space.

There were sharps disposal boxes in each room and at Hospital D this was less intrusive by being located behind the toilet door. It however made the bathroom less of a domestic retreat during labour.

\section{Domain 2: Facility characteristics}

The characteristics of the Facility domain include physical support, a birthing bath and ensuite bathroom facilities. The Optimality Scores for this domain ranged from 59 (Hospital F) to 85 (Hospital B's birth centre). The mean Optimality Score for this domain was 73 points, suggesting that the newer units were achieving a reasonable proportion of these facility characteristics.

\section{Physical Support}

Birthing balls, birthing chairs and floor mats were available in all units. Some were stored in the room cupboards while others were outside. In all the units there were no wall bars or rails for leaning on other than in the bathroom. In many cases there was a table or window ledges that were used for leaning. As previously identified, midwives reported that the bed was often used to lean against. This lack of leaning apparatus was seen as a serious omission since many women choose a forward leaning position in order to ease 
back pain during labour and to facilitate the movement of the baby into an optimal position for birth.

\section{Birthing Bath}

The birth centres at Hospitals A and B, and the labour wards at Hospitals C and E had bathrooms attached to the birthing room, all with big baths. The bath in Hospital B's birth centre was a standard spa depth but did not appear to be deep enough in which to give birth if required. Current evidence suggests that if the baby is to be born into water then the depth of the bath or birth pool should enable the mother's pelvis to be totally under the water when kneeling so that the baby is born completely submerged. The baths all had support bars as required and Hospital C featured a bar especially designed to lean on while kneeling in the bath, which was a useful feature.

At Hospital D, only one birthing room of the four had a bath while across the corridor was a central bath facility. This had been decorated and had a large bath with a privacy curtain across the door. The lights could be dimmed and this would normally have represented an ideal facility if it were not shared and across the corridor from all birthing rooms.

There were no baths available for birthing in the labour wards of Hospitals A, B or F but in each case the bathroom, or the birthing room, was large enough to bring in a portable birth pool.

\section{Bathroom facilities}

All units had birth rooms with their own bathrooms (ensuite bathroom). Generally the size of these rooms was adequate with some being very large $\left(>5 \mathrm{~m}^{2}\right)$. This provided good continuity with access to a shower and toilet without having to leave the space. The hand basins in the ensuite were for women and not for clinical hand washing. Generally, other basins were located in the birthing room for the staff. This was not the case in the Birth centre at Hospital A, where a basin was outside in the corridor as described earlier. 


\section{Domain 3: The aesthetic aspects of the unit}

The characteristics of the Aesthetics domain include light, colour, texture, indoor environment and femininity. The Optimality Scores for this domain ranged from 51 (Hospital F) to 77 (Hospital B's birth centre). The mean Optimality Score for this domain was 66 points indicating an aspect of current design that needs much more consideration.

\section{Light}

Generally, each birth room had natural light. The exception to this was the main room at Hospital F which had a window that had been covered by a large cupboard. The ensuite bathroom had a window, which provided very diffuse light, but essentially this room had no outlook. All the other units had large windows, which provided good light in the daytime.

The majority of the units had very little capacity to vary the light levels. In most cases lights could only be turned on or off. There were generally over-bed lights, which shone upward, and in some case there were strong down lights directly over the bed clearly intended for examination purposes. In the case of the labour ward in Hospital B, there were large operating theatre style examination lights, which gave a very clinical feel. Bright lights indicate that the women in these rooms are under constant surveillance which initiates the fear cascade; labouring under inescapable lights for many hours is also physically debilitating and increases stress.

Staff manipulated the lighting by turning off lights and turning ceiling and wall-mounted examination lights upward or to the wall. These could be used for mood lighting if the other lights were turned off. Lights in Hospitals B and D had dimmers but these were not well maintained so often failed. Similar smaller wall-mounted examination lights were provided over the bed in Hospital C (the newest hospital) suggesting this was not an "old hospital" phenomenon but were still a requirement under current planning guidelines. 
Preference was expressed for a variety of lights in different locations, which could be turned off or left on. Up-lights did provide a softer mood at both the units at Hospital A. The need for strong light for examination and clinical procedures is recognised, however an equal need for softer lighting is also required. Most clinical procedures are internal to the woman and the lighting can be provided using newer fibre-optic technologies that negate the need for operating theatre style lighting.

The ability to increase and decrease lighting levels is an important requirement not generally available in the units. In all units, lights were ceiling or wall-mounted, which made adjustment difficult and reflected a clinical usage with no consideration for mood change. It was not possible to create a "cave like" space (something women often create from furniture arrangements when birthing at home or in birth centres) using the current hospital lights and furniture.

\section{Colour}

In general, the birthing rooms were decorated in pastel colours. Often these were very washed out, creating a cold feeling. Soft shades of beige, yellow and green were used in the labour wards at Hospitals A, B and C, while only in Hospital B's birth centre was there a wall with a strong blue that lifted the sense of joy in the room. The birth centre at Hospital A had a soft pinkish mushroom colour which was more affective but lacked spirit. Staff all expressed a desire to improve the colour schemes and this seems to be an area for immediate improvement.

\section{Texture}

The use of timber style vinyl flooring was an effective attempt to introduce some texture at Hospital C and the labour ward at Hospital A. These stood in contrast to floors that were generally of a neutral colour, shiny and very clinical.

Furniture and fabrics varied enormously with birth centres using couches and curtain material, and labour ward rooms having simple curtains or vertical blinds. Many staff believed it was not possible to use fabrics for curtains or soft furnishings as they would 
not meet fire retardant standards. Timber beds were found in the two birth centres, and in Hospital C there was a round wooden table and chairs, which added a sense of domesticity.

Artworks in the birth rooms were rare. The exceptions were the common areas in Hospital B's labour ward, some pictures of birds in Hospital C, which would have been better as more feminine images, and Hospital A's birth centre, which had appropriate artworks depicting birthing women, in the corridor but not in the birthing rooms.

\section{Indoor Environment}

This is an important aspect of the space since women have need for a variety of different temperatures during birthing. All units had some form of air-conditioning. At Hospital B's birth centre, an oil heater provided additional warmth. The staff in the labour ward in Hospital B complained that one side of the building was hot when the other was cold. This is the normal characteristic of a central air-conditioning system where the heat difference between the faces of the building is significant. There was no temperature control within the rooms at Hospital A, making it cold when the central supply did not heat sufficiently. A cold room potentially creates a hazard for the thermoregulation of newborn babies and increases the likelihood of cold stress for the baby. Generally, additional heaters were required for all birthing units as the degree of control of temperature was poor. Hospital $\mathrm{F}$ had control of temperature only from the central staff base and this thermostat also served the neighbouring ward. Hospital E had a windowmounted air-conditioning system which, when cooling was needed, was very noisy and cold. The ability to open the door to the outside at this site caused the air-conditioning system to pump in cold air, making the environment unpleasant.

In the fully air-conditioned buildings, such as Hospitals A, C and D, windows could not be opened. The use of aromatherapy to improve the indoor environment with oil burners was popular and allowed as long as they were electrically powered. Current ESD (Environmentally Sustainable Design) guidelines will see future units with access to 
natural ventilation and birthing units will be equipped with individual fan-coil or similar units for temperature control.

\section{Femininity}

There were limited examples of feminine shapes (round, curved and soft edges rather than right angled, vertical or horizontal lines) or decorations in the birth units. There were examples of domestic curtains and artworks but none of the birth units had curved walls. Some pieces of furniture (bed heads, chairs and counters) did have curved elements with the intention of avoiding hazards rather than for any expression of feminine symbols.

\section{Domain 4: Essential support elements for women and families}

The characteristics for the Support domain include food and drink for women and their supporters as well as accommodation for companions and staff. The Optimality Scores for this domain ranged from 43 (Hospital F) to 80 (Hospital C). The mean Optimality Score for this domain was 68 points. The scores here suggested that these elements were not well represented and unevenly available, especially in the older units.

\section{Food and drink for women}

The presence of a small fridge for women and families was normal in most units but there was none at Hospital D. This hospital had only a small, rather cluttered family space available for supporters to sit in and use, however there were fold-out lounges in each birthing room, which could be used for supporters to rest. Ice was provided in different locations but generally not readily available. It was usually found in the ward pantry, or in the utility room where it could not be accessed by the labouring woman's birth supporters.

The birth centres at Hospitals A and B had a waiting space for families near the entry equipped with TV, toys for children and appropriate artworks. Hospital E had a separate family resting space complete with TV, kitchenette and a place for siblings to play that led to an outdoor area. The door to this space had a sign saying "No Children Allowed" 
which was rather parent/child unfriendly. Concerns for supervision and issues of insurance make some good intentions unavailable.

Hospital C had a pleasant waiting space outside the birthing room area for visitors, equipped with refrigerator, tea, coffee, magazines and TV. The chairs, however, were upright and not for relaxation or comfort. Hospital C also had small refrigerators available in the birthing rooms. Hospital $\mathrm{F}$ had no family space other than chairs in the entry foyer to the hospital, presumably due to the hospital's general lack of space.

Food preparation areas and availability in all units was limited to fruit juice, tea and coffee and access to various snack food vending machines, usually available in corridors. Only at Hospitals F and E was there a suggestion that the vending machines had healthy options including yoghurt, cereal or fruit. Toasters were generally restricted to staff use in all hospitals due to safety policies and the potential for setting off smoke alarms.

\section{Meals and accommodation for companions and birth attendants}

Meals in most hospitals were available in the cafeteria or cafés during the day but not after 8:00pm. While the women, as patients, were sustained by the hospital food, supporters and family were not provided for, especially late in the evening.

Finally, it was noted in all cases that no provision was made for supporters to change, shower, or in most cases, to use a toilet that was not in the birth room. The conclusion was that supporters are not provided for in departmental planning, even though philosophically they are regarded as an important part of labour and birth.

\section{Internal validity of the BUDSET}

The intra class correlation coefficient was acceptable (at a level of $>0.60$ ) for nine (50\%) of the 18 characteristics. The characteristics that scored the highest included: drop-off area appears safe and well lit; presence of natural light through windows and/or skylights; and, accommodation for companions and birth attendants. Characteristics that scored the lowest were noise control; en suite facilities; and, indoor environment. These latter 
characteristics had intra class correlation coefficients that indicated that the relationship between raters was essentially random.

\section{DISCUSSION}

This pilot study has tested the utility of a newly developed instrument called the BUDSET. The BUDSET aims to discriminate between more or less optimally designed birth spaces, however more work needs to be done to improve the intra class correlation coefficient scores by refining the criteria for the lower scoring characteristics so that raters are able to score the same things in each case. The use of measuring instruments (e.g. a noise measuring meter) may be useful in future analyses. We have calculated, based on previous work in dementia care units that a larger study would need to include 20 sites to ensure that measurement of intra class correlation coefficient has sufficient power. Greater clarity about what is desired by and acceptable to women, especially in the aesthetics domain, will be sought through qualitative research with women to further develop the tool prior to further measurements.

The findings from this pilot study showed that the BUDSET has some discrimination capabilities is assessing birthing unit design. THIS IS THE PULL-OUT QUOTE. Birth centres which are designed as homely, domestic spaces and aim to support physiological birth, scored higher than the more technological environments provided in labour wards. Newer units, for the most part, scored higher than older units although not universally. Arguably, the design of newer units was informed by the needs of both health professionals and women. The differences on each of the four domains of the BUDSET in eight birth units provide evidence of the discriminating ability of the instrument. The next stage of this work is to establish content validity of the BUDSET with pregnant and postpartum women and health professionals. Ultimately we intend to use the BUDSET to investigate our hypothesis that optimal birth unit design supports physiological birth.

The BUDSET domains were useful in identifying aspects of each birth unit that could be improved and those that could not. The most challenging aspects are the configurations 
such as placement of doors, windows and the provision of bathrooms and soundproofing. The BUDSET also highlighted a number of areas where the design was deficient despite being a requirement set out in the design guidelines. For example, the most recent Health Facility Guideline in our state (NSW Health, 2007) allows for a large bath or birthing pool in each birth unit. This, however, was not provided in all birth units in our sample. The consequence of this is that birthing baths are seen as an add-on rather than an essential birthing element and an important component of the management of pain in labour (NICE, 2007). Many of these issues, such as the inclusion of baths, require major structural alterations which current budgets preclude and are best left to new buildings, unless innovative design strategies can be created. The implication of this is that many women are presently birthing in environments that inadequately support them practically, psychologically and socially.

An important element of health facility design is the connection with nature - to enable patients, family and the public to move easily out into gardens and courtyards. This is recognised as an important stress reducing element in the Fear Cascade domain. The underpinning logic for this benefit derives from research associated with "The Biophilia Hypothesis" which establishes the evolutionary connection that humans have to nature (Wilson, 1984). THIS IS THE PULL-OUT QUOTE. Very few units provided opportunities to have a connection with nature. Some of the views from windows were onto bare spaces and other units had no view at all.

Increasingly, evidence is demonstrating benefits for women if they remain upright and mobile during labour, rather than lying on a bed (Gupta, Hofmeyr, \& Smyth, 2006; NICE, 2007). The bed was dominant in all the labour wards in this study. Decreasing the dominance of the bed in the room could be achieved by moving the bed to one side and making it clear that the space is available for the woman to be mobile. If, or when, gas for pain relief is required and the bed is the only place to get it, this could be provided through portable gas and longer connective tubing from wall supplied gas outlets. These are simple mechanisms for achieving flexibility and providing women with freedom to move. Such changes would not require extensive or costly modifications. 
Privacy was not addressed in most birth units studied. There was an unrestricted ability to enter the birthing rooms which made them overly accessible. Often medical and midwifery staff enter without seeking permission, thereby disturbing labouring women, and potentially increasing anxiety and initiating the Fear Cascade. Simple, no cost solutions such as commitment to a policy of asking for permission to enter should be established in all units.

THIS IS THE PULL-OUT QUOTE. The aesthetic domain has the greatest potential for improvement with simple, low cost strategies such as adding feminine artworks and brighter colours to corridors and birth rooms. Normally in clinical environments there is a concern about colours, which will affect skin tone such as yellow (produces a jaundiced effect), red because of blood, or blue, which is usually considered cold. It was clear the policy to maintain soft pastel colours for clinical environments had guided the decisions about colour in most units observed. More consideration could be given to the use of even small amounts of bright colours in birthing rooms. Where the use of round tables and chairs was evident, especially those made of wood, they added a whole sense of domesticity to a birth room. The addition of these would not only provide places for birthing attendants to sit, eat or talk, it would also make the space feel more homely. Similarly, places where women could be supported to lean, such as specially designed shelving, rails or mantelpieces was identified as missing in most units. These could easily be provided at low cost.

Temperature control was also identified as a major problem. Women in labour are likely to want a warmer environment, especially in winter (even winters in warmer climates), so that heaters can be made available. A warm environment is also important for the physiology of newborn thermo-regulation. If the room is warm, women can leisurely pick up their baby after birth, skin-to-skin contact between mother and baby can be encouraged and the initiation of breastfeeding can be facilitated more readily An ability to warm the room was lacking in the units surveyed. The support domain also identified that facilities for supporters is significantly lacking in most birth units and is an aspect 
that could be easily addressed. Including this in the design of the unit at the outset would also ensure that this philosophy of care was able to be included.

One aspect missing from the BUDSET is a more detailed exploration of the needs of staff. It is becoming increasingly well understood that design influences staff satisfaction and stress. A recent, three year multi-method/multi-site study in the UK demonstrated that the design of the maternity unit impacted on staff satisfaction and perceptions of work performance (Symon, 2008a, 2008b, 2008c). Therefore, it is critical to design birth units to reduce or limit stress in women, their support people and staff, which, in turn, could improve communication, team work and job satisfaction.

This study provides one tool that was developed and used in one context. Whilst it might be useful in future design planning or adapted for use in other contexts, we recognise that the study has a number of limitations. Firstly, it was conducted in one country (Australia) and birth practices, cultural expectations, and health care services vary considerably from country to country. Amongst developed countries there is great variance in models of health care and services. When other levels (developing, under-developed) are added, the variance increases significantly. Nonetheless, our instrument highlights some of the important characteristics that might be useful to consider in a range of developed world settings. Secondly, this is an early part of a wider piece of research into birth unit design and further studies are underway to fully explore this concept. Thirdly, the inter-rater reliability shows that certain aspects of the tool are not clear enough and will be adapted for the next round. We recognise that at least 20 facilities are required in a larger study to have an accurate reliability indicator. Further research is also required to undertake content and construct validity testing of BUDSET and correlate the BUDSET results with the outcomes for women and staff. An understanding of feasibility and how a fully optimised environment for the patient may or may not optimise processes and staff working conditions needs to be explored with staff, patients, managers and designers. In addition, clearer definitions of the constructs and the means by which they are measured will be further developed in future research. Ongoing work on the BUDSET is underway and will be the topic of future publications. 


\section{CONCLUSION}

Birth unit design to date has focussed on the needs of staff and perceived need for access to the technological support required for medicalised birth. This may increase anxiety for some women resulting in the initiation of the Fear Cascade and a requirement for the very technology that has been provided. We are just beginning to recognise the needs of the service user and to understand the way that environment can impact on the physiology of childbirth. THIS IS THE PULL-OUT QUOTE. Optimal birth unit design should facilitate physiological birth while at the same time provide additional access to technology for those women and babies who require it. Capital works spending in the area of birth unit design should be focused on creating an optimal environment for all women accessing these facilities. This study demonstrates that there is considerable room for improvement in this regard.

The BUDSET provides a useful tool, describing the design elements that should be considered when refurbishing or planning new birth units that are focussed on supporting physiological birth. Existing units may also benefit from applying the BUDSET to determine which domains may require attention to increase physiological birth support. However in order to get closer to optimal scores of $100 \%$ it would be necessary for most hospitals to employ major construction programs to achieve any real, positive change. 


\section{REFERENCES}

Australian Institute for Health and Welfare (AIHW). (2008). Health Expenditure Australia 2006-07: Health and Welfare Expenditure, Series 35. Canberra: Australian Institute of Health and Welfare.

Davis, S., \& Walker, K. (2009). Re-discovering the material body through an exploration of theories of embodiment. Midwifery, Available from: DOI: 10.1016/j.midw.2008.10.004 (in press).

de Botton, A. (2006). The Architecture of Happiness: The Secret Art of Furnishing Your Life. New York: Penguin.

Dilani, A. (Ed.). (2001). Design and Health - The Therapeutic Benefits of Design. Svensk Byggtjänst: Proceedings of the International Academy for Health and Design.

Donnison, J. (1977). Midwives and Medical Men. London: Heinemann.

Edelstein, E. (2004). Neuroscience and Architecture: Health Care Facilities. Second annual Woods Hole workshop report, sponsored by the Vinyl Institute and the Academy of Neuroscience for Architecture of the American Institute of Architects, August 15-17, 2004.

Fahy, K. (2008). Power and the social construction of birth territory. In K. Fahy, Foureur, M., Hastie, C. (Ed.), Birth Territory and Midwifery Guardianship: Theory for Practice, Education and Research (pp. 3-10). Oxford: Elsevier.

Fleming, R., Baum, J., \& Singer, J. (1984). Toward an integrative approach to the study of stress. Journal of Personality and Social Psychology, 46(44), 939-949.

Forbes, I., Homer, C., Foureur, M., \& Leap, N. (2008). Birthing Unit Design: Researching New Principles. Design \& Health Scientific Review, October, 47-53.

Foureur, M., Hunter, M. (2007). The Place of Birth. In S. Pairman, Pincombe, J., Thorogood, C., Tracy, S. (Ed.), Midwifery - Preparation for Practice. Sydney: Elsevier.

Foureur, M. (2008). Creating birth space to enable undisturbed birth. In K. Fahy, Foureur, M., Hastie, C. (Ed.), Birth Territory and Midwifery Guardianship: Theory for Practice, Education and Research (pp. 57-77). Oxford: Elsevier.

Foureur, M., Leap, N., Davis, D., Forbes, I., \& Homer, C. (2010). Developing the birth unit design spatial evaluation tool (BUDSET) in Australia - A qualitative study Health Environments Research \& Design Journal, In press, accepted on 28 Sep 2009.

Gupta, J., Hofmeyr, G., \& Smyth, R. (2006). Position in the second stage of labour for women without epidural anaesthesia. Cochrane Pregnancy and Childbirth Group 
Cochrane Database of Systematic Reviews, Issue 4 Published by John Wiley and Sons, Ltd.

Hatem, M., Sandall J, Devane, D., Soltani, H., \& Gates, S. (2008). Midwife-led versus other models of care for childbearing women. Cochrane Database of Systematic Reviews Issue 4 Published by John Wiley and Sons, Ltd.

Hauck, Y., Rivers, C., \& Doherty, K. (2008). Women's experiences of using a Snoezelen room during labour in Western Australia. Midwifery, 24(4), 460-470

Hodnett, E., Downe, S., Edwards, N., \& Walsh, D. (2005). Home-like versus conventional institutional settings for birth. Cochrane Database of Systematic Reviews, Issue 1 Published by John Wiley and Sons, Ltd.

Hodnett, E., Stremler, R., Weston, J., \& McKeever, P. (2009). Re-Conceptualizing the Hospital Labor Room: The PLACE (Pregnant and Laboring in an Ambient Clinical Environment) Pilot Trial. Birth, 36(2), 159-166.

Lepori, B., Foureur, M., \& Hastie, C. (2008). Mindbodyspirit Architecture: Creating birth space'. In K. Fahy, M. Foureur \& C. Hastie (Eds.), Birth Territory and Midwifery Guardianship (pp. 95-112). Oxford: Elsevier.

Lepori, B., Foureur, M., Hastie, C. (2008). Mindbodyspirit Architecture: Creating Birth Space. In K. Fahy, Foureur, M., Hastie, C. (Ed.), Birth Territory and Midwifery Guardianship: Theory for Practice, Education and Research (pp. 95-112). Oxford: Elsevier.

Lock, L. R., \& Gibb, H. J. (2003). The power of place. Midwifery., 19(2), 132-139.

Newburn, M., \& Singh, D. (2005). Are Women Getting the Birth Environment They Need? A Report of a National Survey of Women's Experiences London: National Childbirth Trust.

NICE. (2007). Intrapartum care of healthy women and their babies during childbirth. London: RCOG Press at the Royal College of Obstetricians and Gynaecologists.

NSW Health. (2007). NSW Health Facility Guidelines: Post Occupancy Evaluation Guideline - Final Issue February 2007. Sydney: NSW Health.

NSW Health. (2009). NSW Mother's and Babies 2006. Sydney: NSW Department of Health.

Olsen, O., \& Jewell, D. (2006). Home versus hospital birth.(Cochrane Review).

Cochrane Database of Systematic Reviews Issue 4. (Published by John Wiley and Sons, Ltd).

Shorter, E. (1983). A history of women's bodies. London: A Lane. 
Stichler, J., \& Kirk Hamilton, D. (2008 ). Theoretical and Conceptual Frameworks in Research and Practice. Health Environments Research and Design Journal, 1(4), 4-6.

Symon, A., Paul, J., Butchart, M., Carr, V., Dugard, P. (2008a). Maternity unit design study Part 2: Perceptions of space and layout. British Journal of Midwifery, 16(2), 110-114.

Symon, A., Paul, J., Butchart, M., Carr, V., Dugard, P. (2008b). Maternity unit design study Part 3: Environmental comfort and control. British Journal of Midwifery, 16(3), 167-171.

Symon, A., Paul, J., Butchart, M., Carr, V., Dugard, P. (2008c). Maternity unit design study Part 4: Midwives' perceptions of staff facilities. British Journal of Midwifery, 16(4), 228-231.

Symon, A., Paul, J., Butchart, M., Carr, V., Dugard, P. (2008d). Maternity unit design: Background to multi-site study in England. British Journal of Midwifery, 16(1), 29-33.

Tew, M. (1990). Safer Childbirth? A Critical History of Maternity Care. London: Chapman and Hall.

Ulrich, R., \& Barach, P. (2006). Designing Safe Healthcare Facilities-What are the data and where do we go from here? Paper presented at the Healthcare Environments Research Summit.

Ulrich, R., Zimring, C., Xuemei Z, DuBose, J., Seo, H., Choi, Y., et al. (2008). EvidenceBased Healthcare Design. Health Environments Research \& Design, 1, 61-125.

Walsh, D., \& Downe, S. (2004). Outcomes of free-standing, midwife-led birth centers: A structured review. Birth, 31(3), 222.

Wilson, E. (1984). Biophilia. Cambridge: Harvard University Press. 
Table 1: Characteristics of the eight birth units

\begin{tabular}{|c|c|c|c|c|c|}
\hline Hospital & $\begin{array}{c}\text { Type of } \\
\text { Birth } \\
\text { Unit }^{a}\end{array}$ & $\begin{array}{l}\text { Acuity } \\
\text { level of } \\
\text { unit\# }\end{array}$ & $\begin{array}{c}\text { Approx no. } \\
\text { births per } \\
\text { year* }\end{array}$ & $\begin{array}{c}\text { Geographical } \\
\text { location }\end{array}$ & $\begin{array}{c}\text { Year in which } \\
\text { built or most } \\
\text { recently } \\
\text { renovated }\end{array}$ \\
\hline Hospital A & LW & 6 & 4080 & Metropolitan & 1997 (new) \\
\hline Hospital A & BC & & & & \\
\hline Hospital B & LW & 5 & 2464 & Metropolitan & 1991 (new) \\
\hline Hospital B & $\mathrm{BC}$ & & & & \\
\hline Hospital C & LW & 4 & 1038 & $\begin{array}{c}\text { Outer } \\
\text { metropolitan }\end{array}$ & 2005 (new) \\
\hline Hospital D & LW & 5 & 2209 & Regional & $>10$ years ago \\
\hline Hospital E & LW & 3 & 889 & Regional & $>15$ years ago \\
\hline Hospital F & LW & 2 & $<200$ & Rural & $\begin{array}{c}\text { Renovated }<5 \\
\text { years ago }\end{array}$ \\
\hline
\end{tabular}

${ }^{\mathrm{a}} \mathrm{LW}$ : labour ward; BC: birth centre

\#Level of Maternity Unit is based on the NSW Health Department Role Delineations (NSW Health, 2002) - Level 6 hospitals provide tertiary-level care and have neonatal intensive care units, Level 5 caters for moderate and high risk women and babies greater than 32 weeks gestation. Level 4 caters for moderate risk women and babies greater than 34 weeks gestation. Level 3 caters for selected moderate risk women and babies greater than 36 weeks gestation, Level 2 caters for normal risk women and babies greater than 36 weeks gestation.

*Number of births per year is based on the most recent data available (NSW Health, 2009) (NSW Health, 2009) 